\title{
Strength and Elastic Properties of Low-Fine Self-Compacting Concretes Designed with $\mathrm{Nano}^{\mathrm{SiO}_{2}}$
}

\author{
Muhammed Yasin Durgun ${ }^{1,2}$, Hakan Nuri Atahan ${ }^{2}$ \\ ${ }^{1}$ Civil Engineering Department, Engineering Faculty, Bartın University \\ Bartın, Turkey \\ Mydurgun@bartin.edu.tr \\ ${ }^{2}$ Civil Engineering Department, Civil Engineering Faculty, İstanbul Technical University \\ Istanbul, Turkey \\ Atahanh@itu.edu.tr
}

\begin{abstract}
Self-compacting concrete (SCC) is increasingly takes place in construction applications due to its excellent selfcompacting characteristic. It is known that, in order to achieve self-compacting feature, it is necessary to use high volume of fine materials in the mix design with effective superplasticizers. Using high volume of fine materials causes a decrease in the amount of total coarse aggregates. Coarse aggregates have an important role on the strength and elastic properties of concretes. This paper presents the results of an experimental study which investigated the strength and elastic properties of SCC mixtures modified with nano- $\mathrm{SiO}_{2}$. Nano- $\mathrm{SiO}_{2}$, having $35 \mathrm{~nm}$ average particle size, was used with the aim of reducing the total fine material in SCC designs. Five different nano- $\mathrm{SiO}_{2}$ percentages $(0.5 \%, 1.0 \%, 1.5 \%, 2.0 \%$ and $2.5 \%)$ were utilized and the total fly ash content used in the reference mixture was gradually reduced. The volumetric emptiness occurred by the fly ash reduction was filled by aggregates. Successful mixtures which exhibited desired SCC properties were subjected to compressive tests at $28^{\text {th }}$ and $120^{\text {th }}$ days. Moduli of elasticity of concrete specimens were also measured. Results have shown that with increasing W/Cm ratio, compressive strengths were decreased. The use of nano- $\mathrm{SiO}_{2}$ in reduced-fly ash content mixtures could not compensate the strength decrement. However, the use of nano- $\mathrm{SiO}_{2}$ combined with fly ash has prominently enhanced the elastic modulus of nano-modified SCC mixtures.
\end{abstract}

Keywords: Self-compacting concrete, Nano $\mathrm{SiO}_{2}$, Strength properties, Modulus of elasticity

\section{Introduction}

Self-compacting concrete (SCC) is a new generation innovative material by its special properties. These properties such as consolidating under its own weight, filling formworks without any vibration or easier casting for dense reinforced members, makes SCC more popular in the last decades [1,2]. The most general rules in order to obtain self-compacting ability are limiting the coarse aggregate content, lowering the water to binder ratio and using a powerful superplasticizer [3]. High flowability causes tendency of segregation and bleeding during transportation and placing. In order to prevent the risk of segregation and bleeding and to achieve necessary viscosity, it is recommended to increase the amount of fine materials or using viscosity modifying agents [4].

It is known that aggregates play an important role for designing high-performance concrete [5]. In order to improve the mechanical properties of the concrete, strength, brittleness, texture and mineralogy of the coarse aggregates are very important [6]. Mechanical properties of a hardened concrete are directly related to the mix design parameters [7]. For the safety, durability and serviceability of a concrete member, compressive strength, tensile strength and the modulus of elasticity are the most important parameters [8]. Many researchers reported that there is a direct relationship between aggregates and compressive strength of concrete [9 - 13]. Elastic modulus is also related to the stiffness and the characteristics of the phases that constitutes concrete [14]. Therefore elastic modulus directly affected by the aggregate content and some researches showed that aggregates have a very significant effect on elastic modulus [15, 16]. In the literature, it was reported that SCC has lower elastic modulus than conventional concrete since the lower aggregate content and the smaller maximum grain size [17 - 19]. 
Applications of nanotechnology in cement based systems have attracted much attention in recent years. Especially using nano particles in cement based systems has a huge potential [20]. Nano particles, which have enormous specific surface area, leads to extreme chemical reactions and could modify the nano-structure of hardened cement paste. A considerable amount of studies in the literature have reported that nano particles influence the mechanical properties of cement based systems [21-27].

In this study, SCC mixtures modified by nano-SiO2, on the purpose of reducing the total fine material amount has been investigated. In line with this purpose, fly ash which was used as fine material in the mixture designs was gradually reduced. The volumetric emptiness occurred by the reduction of fly ash was filled by aggregates without changing the grain distribution. In this way, total aggregate content was increased. On hardened state, compressive strength and modulus of elasticity of the concrete samples at 28th and 120th days were determined. Thereby, the influence of increased total aggregate content and the use of nano-SiO2 on the mechanical and elastic properties of nano-modified SCC mixtures were examined.

\section{Materials}

CEM I 42.5 type ordinary Portland cement used in the study. Fly ash was obtained from Catalagzi thermal power plant in Turkey. Chemical composition and some physical properties of cement and fly ash are given in Table 1. Four different aggregates were used in the study, which are 0-2.5 mm natural sand, 0-4 mm crushed sand, 4-11 mm (CS I) and 11-22 mm crushed stone (CS II). The densities of the aggregates were 2.63, 2.68, 2.69 and $2.69 \mathrm{~g} / \mathrm{cm} 3 \mathrm{respectively.} \mathrm{Aggregates} \mathrm{used}$ in the study have a fineness modulus of 1.65, 2.49, 5.55 and 6.57 respectively. Cembinder 8 by AkzoNobel was used as colloidal nano silica (CNS) in the study. Properties of nano SiO2 is given in Table 2. The CNS has a solid content of $50 \%$ (50\% $\mathrm{SiO} 2$ and $50 \%$ water by weight). All the replacement rations given in the study for CNS denote net nano SiO2 amounts. As super plasticizer, modified polycarboxylate ether polymer based high performance super plasticizer was used.

Table 1: Chemical composition and physical properties of cement and fly ash.

\begin{tabular}{|l|c|c|c|c|c|c|c|c|c|}
\hline Composition, \%: & $\mathbf{S i O}_{\mathbf{2}}$ & $\mathbf{A l}_{\mathbf{2}} \mathbf{O}_{\mathbf{3}}$ & $\mathbf{F e}_{\mathbf{2}} \mathbf{O}_{\mathbf{3}}$ & $\mathbf{C a O}$ & $\mathbf{M g O}$ & $\mathbf{S O}_{\mathbf{3}}$ & $\mathbf{C l}^{-}$ & $\begin{array}{c}\text { Density } \\
\left(\mathbf{g} / \mathbf{c m}^{\mathbf{3}}\right)\end{array}$ & $\begin{array}{c}\text { Surface area } \\
\left(\mathbf{m}^{2} / \mathbf{g}\right)\end{array}$ \\
\hline Cement & 19.28 & 5.45 & 2.79 & 64.41 & 2.07 & 2.76 & 0.017 & 3.14 & 0.337 \\
\hline Fly Ash & 58.75 & 25.24 & 5.76 & 1.46 & 2.22 & 0.08 & 0.015 & 2.00 & 0.222 \\
\hline
\end{tabular}

Table 2: Properties of colloidal nano $\mathrm{SiO}_{2}$.

\begin{tabular}{|l|c|}
\hline Property & Colloidal Nano $\mathbf{S i O}_{2}$ \\
\hline $\mathrm{SiO}_{2}$ Content, $\mathrm{wt} \%$ & 50 \\
\hline Water Content, $\mathrm{wt} \%$ & 50 \\
\hline Average Particle Size, $\mathrm{nm}$ & 35 \\
\hline Density, $\mathrm{g} / \mathrm{cm}^{3}$ & 1.4 \\
\hline Surface Area, $\mathrm{m}^{2} / \mathrm{g}$ & 80 \\
\hline
\end{tabular}

\section{Experimental Study}

Table 3 shows the mixture designs of concretes showing desired SCC characteristics. CNS was added to SCC mixture by five different amounts which are $0.5 \%, 1.0 \%, 1.5 \%, 2.0 \%$ and $2.5 \%$ of total binder by weight. Besides for each CNS percentage, four different fly ash levels were used. In reference mixture $160 \mathrm{~kg} / \mathrm{m}^{3} \mathrm{fly}$ ash was used and this amount was reduced step by step down to $0 \mathrm{~kg} / \mathrm{m}^{3}$. At every step, $40 \mathrm{~kg} / \mathrm{m}^{3}$ of fly ash was reduced. Volumetric emptiness caused by the fly ash reduction was filled with the addition of aggregates without changing its grain distribution. Mix percentages of aggregates by volume are $22.0 \%, 19.0 \%, 29.5 \%$ and $29.5 \%$ for CS1, CS2, natural and crushed sand, respectively. In this way, the total aggregate volume fraction in SCC mixtures was increased from $59.3 \%$ (for reference mixture) to $66.3 \%$ (for 0FA mixtures). However, the change in coarse aggregate concentration in these mixtures is very limited, i.e. from $24.3 \%$ to $27.1 \%$. Average aggregate volume fractions of the reference and FA mixtures are given in Table 4. 
In order to understand that the mixtures were proper as an SCC, preliminary SCC flowability tests were performed such as $\mathrm{T}_{500}$, D-mean, V-funnel. Some mixtures did not provide SCC properties due to high segregation, bleeding or the loss of consistency. These mixtures accepted as unsuccessful mixtures and denoted with star in Table 3. Unsuccessful mixtures were ignored in the mechanical tests. Mixtures were produced in a laboratory type mixer and cast into cylindrical molds with $100 \mathrm{~mm}$ diameter and $200 \mathrm{~mm}$ height. Samples were demoulded after 24 hours of setting and placed into lime saturated water cure tank. Samples were cured for 28 and 120 days. After curing period compressive strength tests were performed according to TS EN 12390-3 and static elastic moduli of samples were measured according to TS ISO 1920-10.

Table 3: Mixture designs of SCC mixtures $\left(\mathrm{kg} / \mathrm{m}^{3}\right)$.

\begin{tabular}{|c|c|c|c|c|c|c|c|c|c|c|c|}
\hline \multirow{2}{*}{ Mix ID } & \multirow{2}{*}{ W/C } & \multirow{2}{*}{$\mathrm{W} / \mathrm{Cm}$} & \multirow{2}{*}{ Water } & \multirow{2}{*}{ Cement } & \multirow{2}{*}{$\mathbf{F A}$} & \multirow{2}{*}{$\begin{array}{l}\mathrm{Nano} \\
\mathrm{SiO}_{2}{ }^{* *}\end{array}$} & \multirow{2}{*}{ SP } & \multirow{2}{*}{ CS I } & \multirow{2}{*}{ CS II } & \multicolumn{2}{|c|}{ Fine Aggregate } \\
\hline & & & & & & & & & & Nt. Sand & Cr. Sand \\
\hline Reference & 0.46 & 0.33 & 185 & 400 & 160 & 0.0 & 7.84 & 351 & 303 & 460 & 469 \\
\hline FA120/S0* & \multirow{6}{*}{0.46} & \multirow{6}{*}{0.36} & \multirow{6}{*}{185} & \multirow{6}{*}{400} & \multirow{6}{*}{120} & 0.0 & \multirow{6}{*}{7.84} & 362 & 313 & 475 & 484 \\
\hline FA120/S0.5 & & & & & & 2.8 & & 361 & 312 & 473 & 482 \\
\hline FA120/S1.0 & & & & & & 5.6 & & 360 & 311 & 472 & 481 \\
\hline FA120/S1.5 & & & & & & 8.4 & & 359 & 310 & 470 & 479 \\
\hline FA120/S2.0 & & & & & & 11.2 & & 358 & 309 & 469 & 478 \\
\hline FA120/S2.5 & & & & & & 14.0 & & 356 & 308 & 467 & 476 \\
\hline FA80/S0* & \multirow{6}{*}{0.46} & \multirow{6}{*}{0.39} & \multirow{6}{*}{185} & \multirow{6}{*}{400} & \multirow{6}{*}{80} & 0.0 & \multirow{6}{*}{7.84} & 374 & 323 & 490 & 499 \\
\hline FA80/S0.5 & & & & & & 2.8 & & 373 & 322 & 488 & 498 \\
\hline FA80/S1.0 & & & & & & 5.6 & & 371 & 321 & 487 & 496 \\
\hline FA80/S1.5 & & & & & & 8.4 & & 370 & 320 & 485 & 495 \\
\hline FA80/S2.0 & & & & & & 11.2 & & 369 & 319 & 484 & 493 \\
\hline FA80/S2.5 & & & & & & 14.0 & & 368 & 318 & 482 & 491 \\
\hline FA40/S0* & \multirow{6}{*}{0.46} & \multirow{6}{*}{0.42} & \multirow{6}{*}{185} & \multirow{6}{*}{400} & \multirow{6}{*}{40} & 0.0 & \multirow{6}{*}{7.84} & 385 & 333 & 505 & 515 \\
\hline FA40/S0.5* & & & & & & 2.8 & & 384 & 332 & 504 & 513 \\
\hline FA40/S1.0 & & & & & & 5.6 & & 383 & 331 & 502 & 512 \\
\hline FA40/S1.5 & & & & & & 8.4 & & 382 & 330 & 500 & 510 \\
\hline FA40/S2.0 & & & & & & 11.2 & & 381 & 329 & 499 & 508 \\
\hline FA40/S2.5 & & & & & & 14.0 & & 379 & 328 & 497 & 507 \\
\hline FA0/S0* & \multirow{6}{*}{0.46} & & & & & 0.0 & & 397 & 343 & 520 & 530 \\
\hline FA0/S0.5* & & & & & & 2.8 & & 396 & 342 & 519 & 528 \\
\hline FA0/S1.0* & & & & & & 5.6 & & 394 & 341 & 517 & 527 \\
\hline FA0/S1.5 & & 0.46 & 185 & 400 & 0 & 8.4 & 7.84 & 393 & 340 & 515 & 525 \\
\hline FA0/S2.0 & & & & & & 11.2 & & 392 & 339 & 514 & 524 \\
\hline FA0/S2.5 & & & & & & 14.0 & & 391 & 338 & 512 & 522 \\
\hline
\end{tabular}

W/C: Water to cement ratio, FA: Fly ash, SP: Superplasticizer, CS: Crushed stone, Nt. Sand: Natural sand, Cr. Sand: Crashed sand

*Unsuccessful mixtures as SCC, **Pure nano silica amounts.

Table 4: Aggregate volume fractions of SCC mixtures $\left(\mathrm{kg} / \mathrm{m}^{3}\right)$.

\begin{tabular}{|l|c|c|c|}
\hline \multirow{2}{*}{ Mix Code } & \multicolumn{3}{|c|}{ Aggregate Volume Fraction, \% } \\
\cline { 2 - 4 } & Coarse Aggr. & Fine Aggr. & Total \\
\hline Reference mixture & 24.3 & 35.0 & 59.3 \\
\hline FA120 mixtures & 24.9 & 35.7 & 60.6 \\
\hline FA80 mixtures & 25.7 & 36.9 & 62.6 \\
\hline FA40 mixtures & 26.5 & 38.0 & 64.5 \\
\hline FA0 mixtures & 27.1 & 39.1 & 66.3 \\
\hline
\end{tabular}




\section{Results}

\subsection{Compressive Strength Test Results}

In order to specify the compressive strength of the concrete samples, compressive strength tests were performed on 28th and 120th days, according to TS EN 12390-3. The results of compressive strength tests are illustrated in Figures 1 and 2.

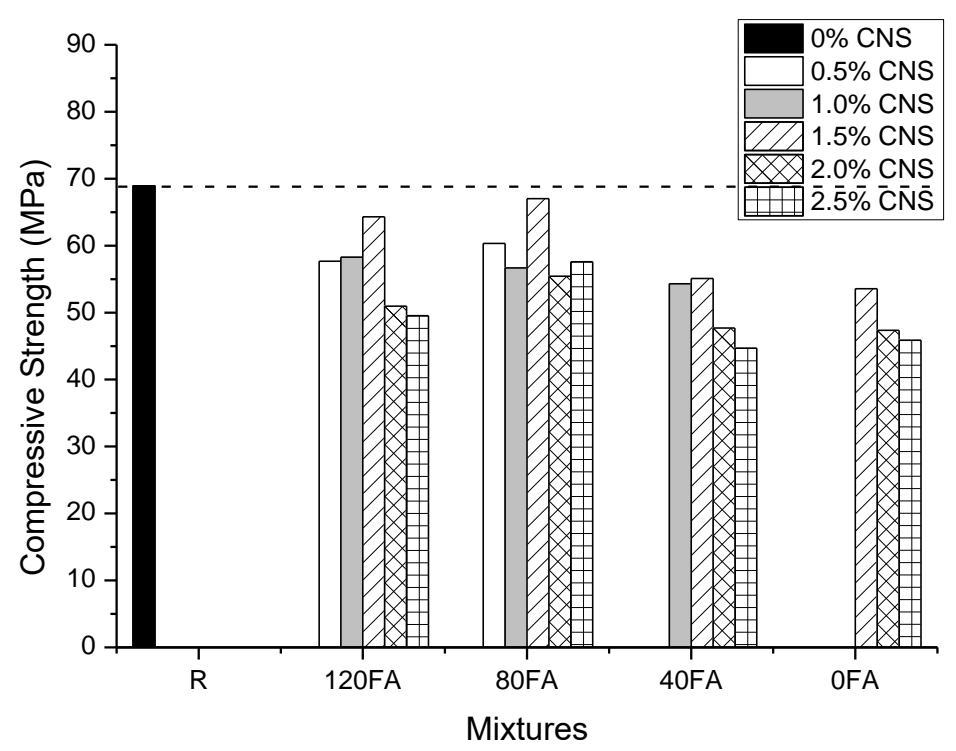

Fig. 1: Compressive strength test results for 28 days.

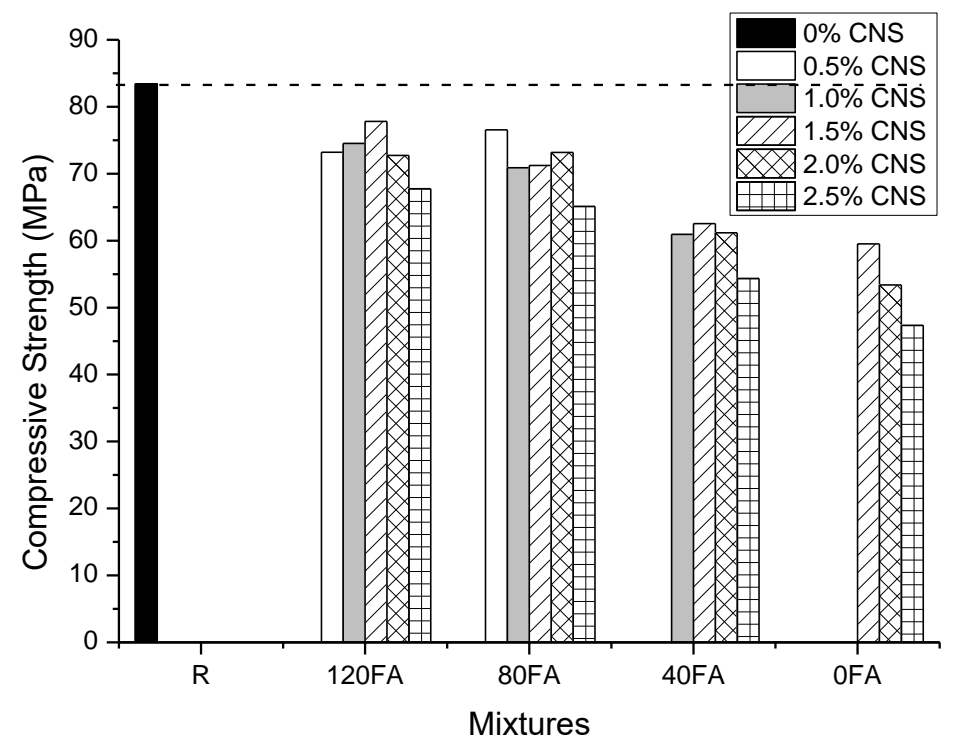

Fig. 2: Compressive strength test results for 120 days.

Results have shown that both on 28th and 120th days reference sample has given the highest compressive strength results. Compressive strength values of $68.9 \mathrm{MPa}$ at 28th day and $83.4 \mathrm{MPa}$ at 120th day were obtained from the reference mixture containing $160 \mathrm{~kg} / \mathrm{m} 3$ fly ash without nano-SiO2. As a general trend, with respect to reference SCC mixture, compressive strength of lower fly ash content mixtures with nano-SiO2 decreased with decreasing fly ash content. Although water to cement ratio (W/C) for all the mixtures is kept constant at 0.46 , increasing water to total binder ratio $(\mathrm{W} / \mathrm{Cm})$ with the reduction of FA content, however, has resulted with the decrement in compressive strengths. It can be 
concluded that the use of nano-SiO2 in reduced-fly ash content mixtures could not compensate the strength decrement. The closest value to reference sample on 28th day was obtained from the mixture 80FA/S1.5 (67.0 MPa). On 120th day, however, the mixture 120FA/S1.5 has shown the closest compressive strength value to reference mixture $(77.8 \mathrm{MPa})$. Based on the compressive strength results shown on Figures 1 and 2 and only considering the mixtures with nano-SiO2, the optimum dosage of nano-SiO2 would be $1.5 \%$.

\subsection{Elastic Modulus Test Results}

In order to understand the effect of adding nano- $\mathrm{SiO}_{2}$ and increasing the total aggregate content on the elastic modulus of SCC samples, elastic modulus test under compression was performed according to TS ISO 1920-10. Elastic modulus test results are shown in Figures 3 and 4.

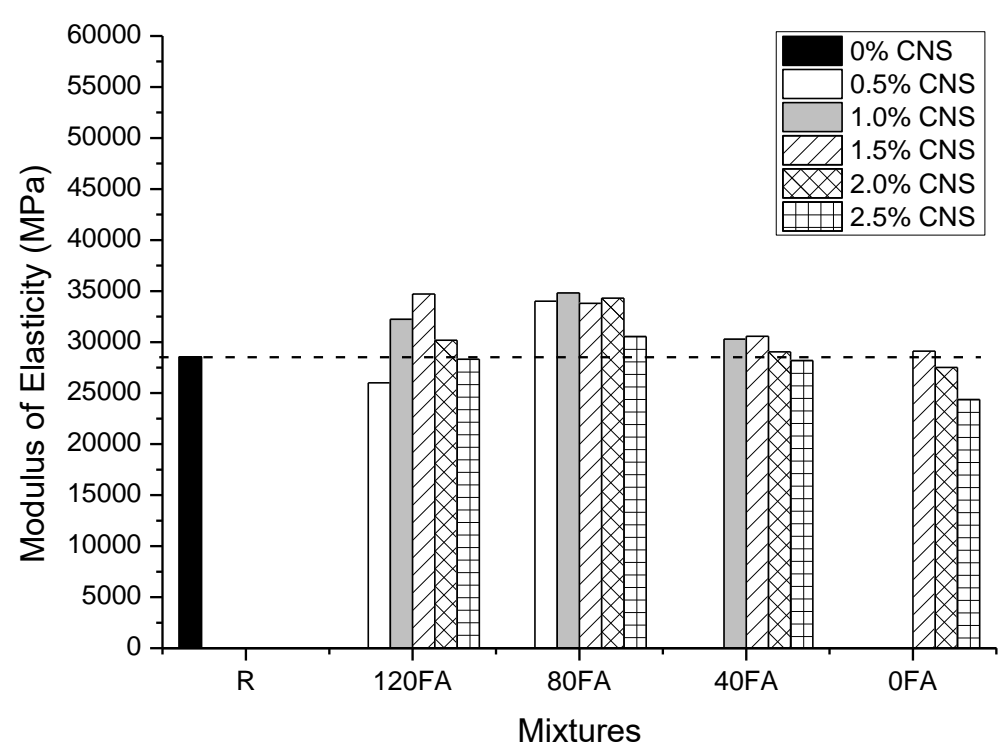

Fig. 3: Elastic modulus test results for 28 days.

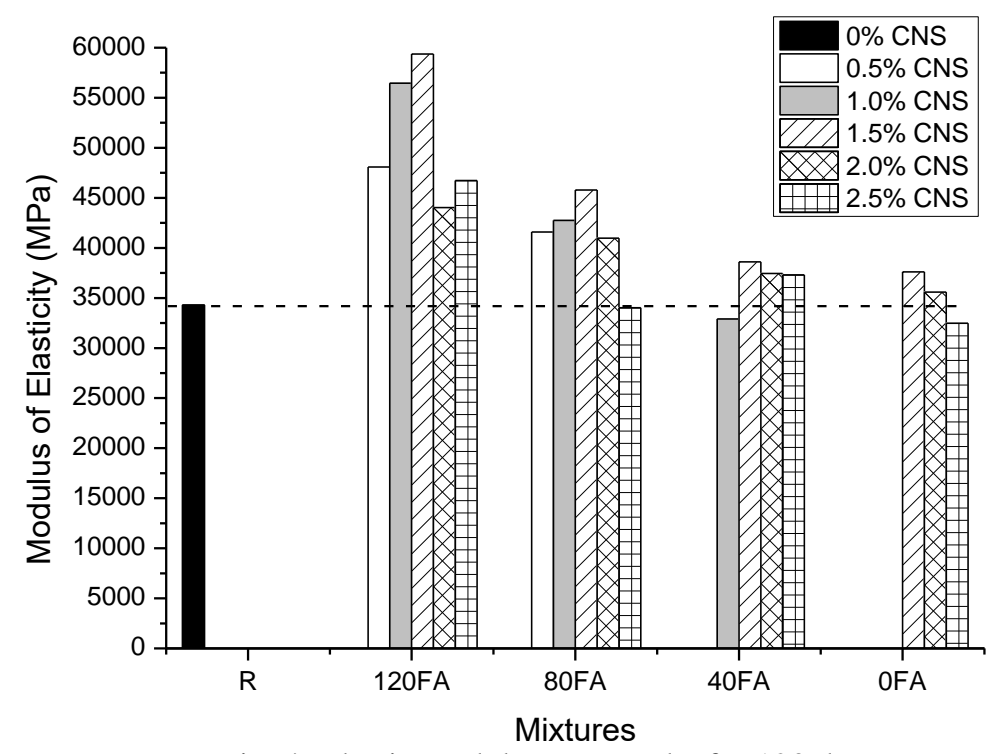

Fig. 4: Elastic modulus test results for 120 days.

On 28th day, a major part of the mixtures and on 120th day, almost all of the mixtures have higher elastic modulus results than reference mixture. The elastic modulus of reference samples was $28.6 \mathrm{GPa}$ on 28th day and $34.3 \mathrm{GPa}$ on 120 th 
day. For the 28 day cured mixtures, $80 \mathrm{~kg} / \mathrm{m} 3$ fly ash containing samples has shown the highest elastic modulus values. Samples in this group have reached up to $22 \%$ higher values than reference sample. $40 \mathrm{~kg} / \mathrm{m} 3$ and no-fly ash samples containing nano-SiO2 have lower elastic moduli than other sample groups but similar to reference mixture. Especially the results for 120th day samples containing nano-SiO2 is noteworthy. On 120th day, $120 \mathrm{~kg} / \mathrm{m} 3 \mathrm{fly}$ ash containing mixtures have shown elastic modulus values "dramatically" greater than the reference mixture. Mixture 120FA/S1.5 has the highest elastic modulus value with $59.4 \mathrm{GPa}$ and this value is $73 \%$ higher than the reference sample. $80 \mathrm{~kg} / \mathrm{m} 3 \mathrm{fly}$ ash containing mixtures have maximum $33 \%$ higher value than the reference mixture. $40 \mathrm{~kg} / \mathrm{m} 3$ and no-fly ash samples, on the other hand, have closer elastic modulus values to reference sample at 120th day. It should be reminded that, with respect to the reference mixture, the compressive strength values of low fly ash mixtures containing nano-SiO2 decreases with the reduction in fly ash content. However, contrary to expectations from the trend in compressive strength change, compared to reference mixture, the elastic modulus values are significantly increased especially for 120FA and 80FA mixtures. From the results obtained, it can be concluded that the increment in elastic modulus of low fly ash nano-SiO2 mixtures (compared to reference mixture) cannot be related to the increment in aggregate volume fractions of these mixtures. In fact, the aggregate volume fractions of the reference and 120FA mixtures are $59.3 \%$ and $60.6 \%$, respectively, which are very similar. Moreover, W/Cm ratio of the reference mixture (0.33) is lower than the W/Cm ratio of 120FA/S1.5 mixture (0.36), and the compressive strength of the reference mixture $(83.4 \mathrm{MPa})$ is slightly higher than the compressive strength of 120FA/S1.5 mixture (77.8 MPa). In order to explain this extraordinary elastic behavior, how the structure of C-S-H gel is effected by the use of nano-SiO2 and fly ash combination should be deeply studied. On the other hand, within the low fly ash nano-SiO2 mixture groups (120FA, 80FA, 40FA and 0FA), although the aggregate volume fractions increases with decreasing fly ash content (from $60.6 \%$ to $66.3 \%$ ), the reduction observed in elastic modulus would be related to the reduction of compressive strengths in these groups.

\section{Conclusions}

Compressive strength and the modulus of elasticity values of samples produced with different amounts of CNS, which was used in order to reduce the total fine material amount and increase the total coarse aggregate content, were investigated. In accordance with the experimental results, following conclusions can be drawn.

1. With respect to reference SCC mixture, compressive strength of lower fly ash content mixtures with nano$\mathrm{SiO} 2$ decreases with decreasing fly ash content.

2. Although water to cement ratio for all the mixtures is kept constant at 0.46 , increasing water to total binder ratio with the reduction of FA content has resulted with the decrement in compressive strengths. The use of nano-SiO2 in reduced-fly ash content mixtures could not compensate the strength decrement.

3. Contrary to expectations from the trend in compressive strength change, compared to reference mixture, the elastic modulus values are significantly increased especially for 120FA and 80FA mixtures containing nano$\mathrm{SiO} 2$.

4. Compared to reference mixture, the increment in elastic modulus of low fly ash nano-SiO2 mixtures could not be explained with the increment in aggregate volume fractions of these mixtures.

5. In order to explain the observed extraordinary elastic behavior of nano-SiO2 containing mixtures, how the use of nano-SiO2 and fly ash combination is effected the structure of $\mathrm{C}-\mathrm{S}-\mathrm{H}$ gel should be deeply studied.

\section{Acknowledgement}

The authors gratefully acknowledge the financial support provided by TÜBİTAK (The Scientific and Technological Research Council of Turkey) as a part of the project number 214M034. The authors would also like to thank KEMIROPA Company for their support providing nano-silica samples.

\section{References}

[1] M. J. Oliveira, A. B. Ribeiro and F. G. Branco, "Curing effect in the shrinkage of a lower strength self-compacting concrete," Constr Build Mater, vol. 93, pp. 1206-1215, 2015.

[2] M. D. Devi, R. Venkatasubramani and R. Elangovan, "Analytical investigation of flextural behaviour of SCC beam using eco sand," International Research Journal of Engineering and Technology, vol. 3, no, 1, pp. 908-913, 2016.

[3] H. Okamura, K. Ozawa, "Mix-design for self-compacting concrete," Concr. Libr. JSCE, vol. 25, pp. 107-120, 1995. 
[4] K. H. Khayat, "Workability, testing and performance of self-consolidating concrete," ACI Mater J, vol. 93, no. 3, pp. 346-353, 2006.

[5] F. de Larrard and A. Belloc, "The influence of aggregate on the compressive strength of normal and high-strength concrete," ACI Mater J, vol. 95, no. 5, pp. 417-425, 1997.

[6] K. Wu, B. Chen, W. Yao and D. Zhang, "Effect of coarse aggregate type on mechanical properties of highperformance concrete," Cem Concr Res, vol. 31, no. 10, pp. 1421-1425, 2001.

[7] A. M. Neville, Properties of concrete. London, 4th ed., Longman, 1995.

[8] I. M. Nikbin, M. H. A. Beygi, M. T. Kazemi, J. V. Amiri, E. Rahmani, S. Rabbanifar and M. Eslami, "A comprehensive investigation into the effect of water to cement ratio and powder content on mechanical properties of self-compacting concrete," Const Build Mater, vol. 57, pp. 69-80, 2014.

[9] A. S. Ezeldin and P. C. Aiticin, "Effect of coarse aggregate on the behaviour of normal and high strength concretes," Cem Concr Aggr, vol. 13, no. 2, pp. 121-124, 1991.

[10] T. Özturan and C. Çeçen, "Effect of coarse aggregate type on mechanical properties of concretes with different strengths," Cem Concr Res, vol. 27, pp. 165-170, 1997.

[11] H. Beshr, A. A. Almusallam and M. Maslehuddin, "Effect of coarse aggregate quality on the mechanical properties of high strength concrete," Constr Build Mater, vol. 17, pp. 97-103, 2003.

[12] M. Uysal, "The influence of coarse aggregate type on mechanical properties of fly ash additive self-compacting concrete," Constr Build Mater, vol. 37, pp. 533-540.

[13] P. C. Aiticin and P. K. Mehta, "Effect of coarse aggregate characteristics on mechanical properties of high strength concrete," ACI Mater J, vol. 82, no. 2, pp. 103-107, 1990.

[14] M. G. Alexander and S. Mindess, Aggregates in concrete (Part 1). University of Witwatersrand, South Africa, Hippo Quarries Technical Publication, 1990.

[15] S. Ahmad and S. A. Alghamdi, "A study on effect of coarse aggregate type on concrete," Perform Arab J Sci Eng, vol. 37, pp. 1777-1786, 2012.

[16] F. P. Zhour, F. D. Lydon and B. I. G. Barr, "Effect of coarse aggregate on elastic modulus and compressive strength of high performance concrete," Cem Concr Res, vol. 25, no. 1, pp. 177-186, 1995.

[17] F. Jacobs and F. Hunkeler, "Design of self-compacting concrete for durable concrete structures," in First International RILEM Symposium on Self-Compacting Concrete, Stockholm, Sweden, 1999, pp. 397-410.

[18] D. Bonen and S. P. Shah, "The effects of formulation on the properties of self-consolidating concrete," in International RILEM Symposium on Concrete Science and Engineering: A Tribute to Amon Bentur, Evanston, USA, 2004, pp. 43-56.

[19] J. Ambriose and J. Pera, "Desing of self-leveling concrete," in First North American Conference on the Design and Use of Self-Consolidating Concrete, Chicago, IL, 2002, 140-144.

[20] S. Chitra, S. R. R. Senthil Kumar and K. Chinnaraju, "The effect of colloidal nano-silica on workability, mechanical and durability properties of high performance concrete with copper slag as partial fine aggregate," Constr Build Mater, vol. 113, pp. 794-804, 2016.

[21] A. M. Mohamed, "Influence of nano materials on flextural behavior and compressive strength of concrete," $H B R C$ Journal, vol. 12, no 2, pp. 212-225, 2016.

[22] J. Björnstörm, A. Martinelli, A. Matic, L. Börjesson and I. Panas, "Accelerating effects of colloidal nano-silica for beneficial calcium-silicate-hydrate formation in cement," Chemical Physics Letters, vol. 392, pp. 242-248.

[23] M. Jalal, E. Mansouri, M. Sharifipour and A. R. Pouladkhan, "Mechanical, rheological, durability and microstructural and thermal properties of high strength self-compacting concrete," Mechanics of materials, vol. 61, pp. 11-27, 2013.

[24] H. Li, H. Xiao and J. Ou, "A study on mechanical and pressure-sensitive properties of cement mortar with nanophase materials," Cem Concr Res, vol. 34, no. 3, pp. 435-438, 2004.

[25] A. Nazari and S. Riahi, "Microstructural, thermal, physical and mechanical behavior of the self-compacting containing $\mathrm{SiO}_{2}$ nanoparticles," Materials Science and Engineering A., vol. 527, no. 11-12, pp. 7663-7672, 2010.

[26] A. Nazari and S. Riahi, "The effects of $\mathrm{SiO}_{2}$ nanoparticles on physical and mechanical properties of high strength self-compacting concrete," Composites Part B: Engineering, vol. 42, no. 3, pp. 570-578, 2011.

[27] Y. Qing, Z. Zenan, S. Li and C. Rongshen, "A comparative study on the pozzolanic activity between nano-SiO${ }_{2}$ and silica fume,” Journal if Wuhan University of Technology, vol. 21, no 3, pp. 153-157, 2006. 